\title{
INTERMEDIATE PEER CONTEXTS AND EDUCATIONAL OUTCOMES: DO THE FRIENDS OF STUDENTS' FRIENDS MATTER?
}

\begin{abstract}
Sociologists of education have long been interested in the effects of peer relations on educational outcomes. Recent theory and research on adolescence suggest that peers on the boundaries of students' friendship networks may play an important role in shaping behaviors and educational outcomes. In this study, we examine the importance of a key "intermediate peer context" for students' outcomes: the friends of a student's friends. Our findings indicate both friends' and friends' friends' characteristics independently predict students' college expectations and their risk of dropping out of high school (although only friends' characteristics predict GPA). Our models suggest the magnitude of students' friends-of-friends' characteristics are at least as large their friends' characteristics. Together, the association between the peer context and students outcomes is considerably larger when accounting for both the characteristics of students' friends and the friends of their friends.
\end{abstract}




\section{INTERMEDIATE PEER CONTEXTS AND EDUCATIONAL OUTCOMES: DO THE FRIENDS OF STUDENTS' FRIENDS MATTER?}

Sociologists of education have long been interested in the effects of peer relations on educational outcomes. Indeed, some of the earliest studies of adolescents in American schools were centrally focused on the importance of peer relationships in students' lives. Hollingshead (1949) focused on the importance of "cliques" in reproducing class boundaries among adolescents, and Coleman (1961) examined how members of the "leading crowd" affected students' social lives and expectations regarding school performance. Interestingly, subsequent research has focused overwhelming on two types of "peer" influences: (1) students' friends, or (2) students' schoolmates (e.g., SES or race-ethnic composition of the school). At one extreme, researchers have studied students' most immediate and affectively intense social relationships (friendship ties), while at the other, scholars have focused on the broadest and most encompassing peer context (school composition). Many fewer studies by sociologists examine the importance of "intermediate" peer relationships and contexts that lie between friendship networks and school composition for student outcomes.

While the effects of friends' characteristics have received much attention from researchers, recent research suggests a different set of social ties - relations with the friends of one's friends - is both theoretically interesting and substantively important to study. Researchers have found the characteristics of the friends of one's friends are important for physical health (Christakis and Fowler 2007, 2008), mental health (Baller and Richardson 2009), and deviant behavioral outcomes (Kreager and Haynie 2011; Payne and Cornwell 2007). Recent work on adolescence (Frank et al. 2008; Giordano 2003; Steinberg 1996) suggests that students may be influenced by both their immediate friendship ties, but also their more distal ties that lies just 
beyond their friendship network. For example, some researchers (e.g., Frank et al. 2008; Payne and Cornwell 2007) have argued that students may use conformity as a strategy to establish new friendship ties with peers.

In this paper, we investigate how the characteristics of a student's friends and his/her friends' friends are related to three academic outcomes: grades, college expectations, and high school completion. We hypothesize that students can directly benefit from their friends' knowledge and academic skills to improve their own academic performance, but friends-offriends characteristics should be less important for this outcome. In contrast, we expect friendsof-friends' characteristics should matter more for outcomes such as college expectations and high school completion because students may use attitudinal and behavioral conformity to their friends' friends to solidify their existing friendship ties, and also to establish new friendship ties. Overall, our findings indicate that the characteristics of students' friends' friends had the strongest association with the student outcomes for which attitudinal and behavioral conformity should matter most: high school completion and college expectations.

Friendships, Peers, and Academic Outcomes

Although the terms "friends" and "peers" are frequently used interchangeably by researchers, it is important to distinguish between them. A "friendship" is an affective tie between individuals that entails a social role, with accompanying expectations of trust, reciprocity, privacy, altruism, favoritism, etc. (Call and Mortimer 2001; Savin-Williams and Berndt 1990). Friendships may be reciprocal (i.e., both individuals consider each other a friend) or asymmetrical (i.e., one individual considers the other a friend, but s/he does not reciprocate). Friendships may also differ in intensity: some friends are "best" friends, and others are casual friends. In contrast, we define "peers" as non-friends who attend a given student's school. 
Unlike friendships, there is no social role associated with peer relations: expectations of trust and reciprocity that are typical in friendships are not applicable with peers (Giordano 2003).

Students know some of their peers by name and/or appearance, and interact with them fairly regularly, while others remain strangers.

Measures of school composition (e.g., percent minority, percent free lunch) combine a student's friends and peers into the same group. In heterogeneous schools, a student's friendship network will likely differ from the overall composition of the school due to homophily (Flashman 2012; Kandel 1978) and within school sorting practices such as curricular tracking (Moody 2001). In contrast, measures of friendship networks and friends' characteristics focus on a subset of the school population: the group of friends that is specific to each individual student. ${ }^{1}$

Numerous studies suggest that the characteristics of a student's friends are related to his/her academic achievement (test scores and grades) (Battin-Pearson et al. 2000; Cook et al. 2007; Vaquera and Kao 2008), academic engagement (Berndt and Keefe 1995; Vaquera and Kao 2006), chances of finishing high school (Cairns, Cairns, and Neckerman 1989; Jimerson et al. 2000; Ream and Rumberger 2008; South, Haynie, and Bose 2007), and educational expectations (Hauser, Tsai, and Sewell 1983). A voluminous literature on peers also documents the importance of a school's racial, socioeconomic, and ability composition for student outcomes, (see Hanushek and Rivkin 2006; Konstantopoulos 2006; Perry and McConney 2010; Willms 2010). In this paper, we argue that "intermediate" groups of peers, who occupy the social space between friends and schoolmates, are both theoretically interesting and relatively understudied. Intermediate Peer Contexts: Between Friendship and School Composition Effects 
Coleman's study of the "adolescent society" in high schools of the late 1950s is a classic example of research on the intermediate peer context. His research includes a detailed description of the important subgroups (and accompanying subcultures) within the school that extended well beyond students' immediate friendship networks. Steinberg (1996) found that almost all students belong to a "crowd," which consists of "like-minded individuals who share certain features in common with each other but who are not necessarily each other's friends" (p.139). Thus, the crowd serves as a reference group that provides a shared identity (rather than intimacy) for adolescents as they judge which behaviors and choices are "appropriate" for themselves and others like them (also, see Brown et al. 1994). Numerous qualitative studies (Carter 2007; Eckert 1989; Kinney 1993; MacLeod 2010; Milner 2006; Ogbu 2003) have identified similar social boundaries within schools that separate students into different subgroups that are characterized by their own values, norms, and cultures.

Frank et al. (2008) examined a different intermediate peer context in their research. Using network data from the Add Health data set, Frank et al. (2008) identified clusters of students across classes within schools, which they called "local positions." Frank et al. argue students are more likely to have regular contact with members of their local position, and new friendships and social ties will likely emerge from this broader peer context. Female students who shared the same local position were more likely to experience similar math course sequences by the end of high school (Frank et al. 2008).

In this paper, we focus on an intermediate peer context that has been virtually ignored in educational research: the friends of a student's friends. In figure one, we present a hypothetical sociogram that shows a student ("ego") who has a direct tie to three friends ("friend one," "friend two," and "friend three"). "Friend one" and "friend two" also share a friendship tie with each 
other, which means that ego, "friend one," and "friend two" are all one-step away from each other and experience "triadic closure." The friendship ties for this triad are "transitive," which means that "friend one" and "friend two" are both friends to ego, and friends-of-friends to ego. In contrast, the sociogram also shows that "friend one" has a direct friendship tie to "friend's friend two" who has no direct tie to ego, and is therefore two steps away. The absence of this direct tie to ego means that "friend's friend one" is an intransitive friendship tie (denoted by the dashed line) for ego. The figure identifies two others who are intransitive friends-of-friends with ego: "friend's friend two" and "friend's friend three." It also identifies an alter ("peer") who is three steps away from ego, and therefore does not count as either a friend or a friends' friend. In this paper, we are interested in the importance of intransitive friends' friends (or, indirect friendship ties) who are two steps away from the focal student.

\section{INSERT FIGURE ONE ABOUT HERE}

The importance of friends' friends, where alters are two steps removed from ego, has been examined in several domains. Christakis and Fowler $(2007,2008)$ found similarity in obesity and smoking among adults and members of their social network for up to three degrees of separation. There is also evidence of the influence of friends' friends among adolescents. Payne and Cornwell (2007) found adolescents were more likely to participate in deviant behaviors if the friends of their friends are deviant (net of the deviance of students' friends). Baller and Richardson (2009) found adolescents who were "at-risk" for suicidal thoughts were significantly more likely to experience such thoughts if they had friends-of-friends who attempted suicide. Finally, Kreager and Haynie (2011) found the drinking behavior of the friends of a subject's romantic partner was related to his/her own drinking, even after controlling for the subject's partner's prior drinking, and the drinking behavior of the subject's friends. 
Interestingly, despite the great interest in a student's friends' characteristics on educational outcomes, no studies have examined the importance of friends-of-friends for educational outcomes. We argue recent theorizing provides a strong justification for an empirical examination of how students' direct and indirect friendship ties are related to educational outcomes.

\section{Why Friends and the Friends' Friends Matter for Educational Outcomes}

Giordano (2003) describes three reasons why friends should affect each other's behaviors and attitudes: “(a) frequent interaction and communication creates numerous opportunities for influence, (b) actors tend to identify most readily with individuals perceived similar to themselves ... and (c) the more that individuals value particular affiliations, the more willing they may be to accede to any influence attempts to maintain or enhance their relationships" (pp.263-4). Similarly, Payne and Cornwell (2007) point out "diffusion" is an important way in which friends affect each other: friends share information and resources because they have regular, direct contact with each other. Indeed, diffusion can only occur when direct ties between individuals are present (DiMaggio and Garip, 2012). In addition, the affective tie between friends makes shared information more trustworthy and valuable. Friends are important sources of social capital within schools.

Research also suggests the similarity between students and their friends is due to both self-selection and social influence. In her seminal study, Kandel (1978) found similar adolescents were likely to form friendships, but she also found friends became more similar over time. Her analyses indicated friendships were equal parts self-selection (homophily) and influence. Lomi et al. (2011) found a similar pattern of self-sorting and social influence in their study of academic performance and advice sharing among Italian graduate students. Finally, Flashman's (2012) 
findings also indicate students self-select their friendship ties based on their academic performance.

While there is less theorizing and research on the possible effects of "friends' friends" on students outcomes, we argue this group is theoretically interesting and important because student are likely to be personally acquainted with their friends' friends. Giordano (1995) notes students are likely to observe and interact with students' friends' friends either in class and/or out of school, and thus, they are likely to be much more influential than members of the social group that are rarely seen by or known to a given student.

There are three main reasons why students would conform to the expectations of their friends' friends. First, students likely see some of their friends' friends as candidates for future direct friendship ties. Much research indicates the importance of homophily, or "assortative pairing" as the main basis of forming friendship ties (see Flashman 2012; Kandel 1978; and Mouw 2006 for a review). Similarity induces "liking" (Kandel 1978; McPherson, Smith-Lovin, and Cook 2001), and conformity to the expectations and behaviors of friends' friends can serve as a useful strategy for transforming these indirect relations into direct friendship ties. This is consistent with research on social networks that indicate networks co-evolve toward "triadic closure" over time, which means intransitive ties are likely to become direct ties in the future (Kossinets and Watts 2006).

Second, students may also view friends' friends as potential threats who could potentially undermine their standing within their social group (Giordano 1995), and weaken their friendship ties. Since these friends' friends are not bound by the norms that characterize direct friendship ties (e.g., trust, reciprocity, privacy), they may openly question a student's membership within the group when non-conforming behavior is observed. Consequently, friends-of-friends may 
potentially weaken one's friendship ties, and students may view attitudinal and behavioral nonconformity as more risky when their friends' friends are present.

Finally, Payne and Cornwell (2007) argue students try to imitate the behavior of more distal peers because they are acting strategically to strengthen their own friendship ties. Both similarity and novelty are valued within friendships, and while friendships allow for some individuality and non-conformity (Call and Mortimer 2001), it is risky for students to be too different from their friends. Consequently, students look for behavioral models that are most likely acceptable to their friends: the actions and behaviors of their friends' friends. Thus, according to Payne and Cornwell, the characteristics of one's friends' friends should affect one's behavior, above and beyond the characteristics of one's friends. Indeed, they found the delinquency of one's friends' friends predicted a student's own delinquency, after controlling for a student's friends' delinquency.

\section{Friends-of-Friends' Characteristics and Educational Outcomes}

As outlined above, prior theory suggests students should seek to conform to expectations and norms established by their friends and friends' friends. Prior research has consistently shown the grades and behaviors of students' friends are related to a student's academic achievement (test scores and grades) (Battin-Pearson et al. 2000; Cook et al. 2007; Vaquera and Kao 2008), chances of finishing high school (Cairns, Cairns, and Neckerman 1989; Jimerson et al. 2000; Ream and Rumberger 2008; South, Haynie, and Bose 2007), and educational expectations (Hauser, Tsai, and Sewell 1983). We will investigate the importance of both friend and friend-offriend characteristics for these important and well-studied outcomes.

We expect the relative importance of friends' and friend-of-friends' characteristics should vary depending on the outcome being studied. We argue characteristics of a student's friends' 
friends should matter most strongly for behaviors/outcomes that are shaped heavily by group norms. We will illustrate by comparing three well-studied academic outcomes: academic grades, high school completion, and college expectations.

For academic grades, we anticipate students will use their friends as academic resources by studying with them, learning from them, and sharing information/knowledge about homework, assignments, and exams, etc. Thus, having friends who have high academic ability, good study habits, and earn good grades should provide significant direct benefits to students through diffusion processes, whereby skills and information are transmitted via their friendship tie. In contrast, academic resources held by one's friends' friends should not benefit students because students typically do not study with and seek assistance from non-friends. In addition, the friends of one's friends are unlikely to affect a student's grades because information about grades is not publicly shared outside of a student's friendship network, and consequently, friends' friends cannot provide direct feedback on a student's academic performance.

In contrast, we expect the characteristics of one's friends' friends should affect a student's risk of dropping out and his/her college expectations because these outcomes are affected more strongly by behavioral and attitudinal conformity to their friends' friends' expectations. For example, unlike academic grades, students can directly observe their friends' friends engaging in (or refraining from) many of the risky behaviors leading to dropping out skipping class, deviance and delinquency, detachment from school, etc. Students may conclude engaging in these risky behaviors might strengthen their existing friendship ties by showing their friends that they are like their friends' friends. Students might also engage in these behaviors in a strategic effort to use homophily to form new friendship ties with their friends' friends. By 
increasing their chances of engaging in these behaviors, friends' friends' characteristics may increase the student's risk of dropping out.

\section{Hypotheses}

Research on the importance of intermediate peer contexts for educational outcomes is relatively scarce, and we argue the friends of a student's friends are a theoretically important group to study. Based on our review of the literature, we propose two hypotheses:

H1: The characteristics of a student's friends will matter more for a student's grades than the characteristics of a student's friends' friends.

H2: The characteristics of a student's friends' friends will matter more for high school completion and college expectations than for academic grades.

Our analyses will make three important contributions to the literature on friendship ties and intermediate peer contexts. First, prior research on friends' characteristics and educational outcomes is too narrow, and may have overlooked an important source of peer influence (friends-of-friends' characteristics). If so, these studies have failed to adequately describe how the broader peer context is related to student outcomes. Second, studies that solely focus upon students' friends' characteristics may have overestimated the impact of friends' characteristics on student outcomes. Since there is undoubtedly similarity between the characteristics of a student's friends and his/her friends' friends, it is possible studies that omit such measures have reported upwardly biased estimates of friends' characteristics (if friends' friends' characteristics do in fact independently affect student outcomes). Indeed, some studies (e.g., Frank et al. 2008; Kreager and Haynie 2011) show friends' characteristics become statistically insignificant when controlling for measures of intermediate peer contexts. Finally, if different levels of the peer context (e.g., both friends and friends' friends) are independently related to educational 
outcomes, prior research may have underestimated the cumulative magnitude of these relationships, and understated the importance of friends and peers for academic outcomes.

\section{DATA/METHODS}

We analyzed data from the National Longitudinal Study of Adolescent Health (Add Health). In the fall of 1994, the entire student body of one hundred thirty-two schools was asked to answer an in-school survey. Approximately $80 \%$ of eligible students participated in the initial survey, totaling 90,118 students ranging in grade from 7-12. Survey items provide in-depth information of students' experiences in school and daily lives outside of school. In the wave one in-school survey, students were asked to nominate up to five male and five female students in the school as their friends. This unique feature of the Add Health data allows researchers to construct the social networks within schools. ${ }^{2}$ A one-fifth subsample of students was selected to participate in follow-up waves of data collection.

All predictor variables included in the analyses were drawn from the in-school wave of data collection conducted in the fall of 1994 (see table one). ${ }^{3}$ Two of our outcome variables grade point average, and college expectations - were extracted from the in-home survey from wave one (collected from April through December of 1995). Our third outcome variable - high school dropout - was measured in the third survey wave (during the 2001-2 school year). (For further description of the Add Health database see Harris et al. [2008].) The descriptive statistics for all of the variables used in our analyses are presented in table one.

\section{INSERT TABLE ONE ABOUT HERE}

\section{Dependent Variables}


The three dependent variables in our analyses come from the follow-up waves of data collection. In the Wave I In-Home survey (Spring 1995), students were asked about their course grades. Our outcome measure of GPA is the average of the student's grades in mathematics, English, history, and science classes from the previous semester. We also examine college expectations in the Wave I In-Home survey of Add Health as an outcome. We create a dichotomous variable that separates students in the highest category of college expectations from students who are in any category below it. We used this relatively high cut-point for college expectations because students' college expectations are heavily skewed: on a five point scale, $57 \%$ of students reported the highest category of likelihood to go to college. Finally, high school completion is measured from student reports of degree attainment during the six year follow up survey conducted in 2001-2002. The timing of this wave of data collection should allow all students adequate time to complete high school (assuming no grade retention). Students who reported having attained no high school degree as well as those who report receiving a General Equivalency Degree (GED) were coded as dropouts in this study. Students reporting they were still attending high school are not included in the analyses as it remains unclear whether these students will drop out or complete school.

\section{Social Network Measures}

In Add Health, each student was asked to nominate up to five male and five female friends. These nominations allow researchers to map the student social networks within schools. The most proximal level of students' social networks is students' immediate friends. We measured friends as those nominated as friends by the student. Next, we identified students' friends of friends by including any student who was nominated as a friend by someone the respondent nominated as a friend. Thus, the direction of nomination is out-going from the 
student to the immediate friend and out-going from the friend to friend-of-friend. Any alter who has a direct friendship tie with a student is not included as a friend-of-friend in the analyses. (See figure one.)

It is important to note the limit of five male and five female nominations could potentially affect our measure of friend-of-friend networks. For example, a student with seven male friends would have to omit two friends, and these respondents would be counted as friendsof-friends if one of the student's listed friends shared a tie with these omitted friends. Moody (2001) documents that $3 \%$ of respondents in Add Health nominated 10 in-school friends, and we observed that roughly $42 \%$ of students named five friends of either gender in the Add Health survey. Moody (2001) notes prior research suggests close friendship groups generally have five to six members, which is largely consistent with the patterns observed in Add Health. We believe any omitted friends who are erroneously included in our friends-of-friends networks should have a negligible impact on our friends-of-friends measures because these networks are relatively large - an average of 19 respondents, which is far larger than what we would expect the number of omitted friends to be. In addition, since it is likely students named their five closest friends of each gender, any friends who were omitted (due to truncation) represented the affectively weakest friendship ties that students have. Thus, we argue our friends-of-friends measures are a very reasonable approximation of the actual friends-of-friends networks.

For our analyses that predict student GPA, we created a measure the average GPAs of students' friends, and a separate measure of a student's friends' friends' GPA. Similarly, in predicting whether a student had high college expectations, we separately measured the percentage of friends and friends' friends who reported "certainty" in graduating from college. Finally, in predicting whether a student completed high school, we created separate measures of 
friends' and friends' friends' "dropout risk," based on six achievement-related characteristics of the members of students' social group and how these characteristics are related to drop out. ${ }^{4}$ The models that predict high school drop out take the average "dropout risk" of students' friends and their friends' friends. These measures provide two mutually exclusive social contexts to include as predictors in our models.

\section{Control Variables}

In all of the models presented, we control for other measures that are related to educational outcomes. Deviance is operationalized as a scale of items that measure how frequently the respondent: gets drunk on alcohol, smokes cigarettes, lies to parents or guardians, skips school, and gets into physical fights. Following South et al. (2007), we created scales to measure school engagement $(\alpha=0.82)$ by how frequently the student has trouble completing homework and paying attention during class (both reverse coded) and attachment to school ( $\alpha=0.79$ ) by how much the student feels like a part of his or her school, is close to people at school, and likes his or her school. Each of these three measures are unweighted scales that average a student's responses based on the number of items.

In addition, we control for a number of important demographic characteristics. These include: race, gender, parental education, parental occupation, and whether the student was born in the United States. Since the Add Health data set included such a wide range of grade levels in its sample, we controlled for the student's grade level in the base year. To control for student academic ability we included students' scores on the Peabody Picture Vocabulary Test (PPVT). Analytical Issues 
All of the models we present include variables from two different waves of the AddHealth survey, and each follows the same basic structure. Below, we present the equation for our model that predicts "grade point average":

$$
G P A_{T 2}=\beta_{0}+\beta_{1} G P A_{T 1}+\beta_{2} X_{T 1}+\beta_{3}\left({\overline{\mathrm{F} \_} \mathrm{GPA}_{T 1}}\right)+\beta_{4}\left({\overline{\mathrm{F} \_} \mathrm{F}_{-} \mathrm{GPA}_{T 1}}\right)+\ldots+\varepsilon
$$

On the left hand side, the outcome variable $\left(G P A_{T 2}\right)$ is measured at the second time point in Add Health (the wave I in-home survey). On the right hand side, all of the covariates are drawn from the first Add Health time point (the wave-I in-school survey), and they include each student's initial GPA $\left(G P A_{T 1}\right)$, a vector of controls variables $\left(X_{T 1}\right)$, and the main variables of interest in the model: the mean GPA $\left(\bar{F} \_G P A_{T 1}\right)$ of a student's friends, and the mean GPA of a student's friends' friends $\left({\bar{F}{ }_{-} F_{-} G P A_{T 1}}\right)$. By controlling for the student's grades from the base year survey (the lagged outcome), we are accounting for the cross-sectional associations between a student's initial grades, his/her friends' grades, and his/her friends' friends' grades. Thus, any association between friends' GPA and friends' friends' GPA and a student's grades at time two will be above and beyond the initial self-selection of students based on academic grades at time one. The models that predict high college expectations and high school dropout follow the same basic structure as the model presented above.

The addition of the lagged dependent variable as a predictor in each regression substantially decreases the magnitude of the relationships friends,' friends-of-friends', characteristics, and the three outcomes we examine. This is not surprising, since we expect initial self-sorting partly accounts for the observed similarity between students, their friends, and their friends' friends (see Flashman 2012). However, while our lagged models address eliminate some self-selection, we recognize our analyses cannot capture the dynamic causal processes that 
underlie the associations in our models. Thus, we refrain from using language that suggests causal relationships when describing the results.

Since our main goal is to estimate the relationship between students' friendship ties, the intermediate peer context, and student outcomes, we use school level fixed effects, where a dummy variable for each school (minus one) is added to the regression to control for schoollevel differences in our regression models. This eliminates "between school" variation in the outcomes from our analyses, and it allows us to control for cross-level confounding due to unobserved variables at the school level. ${ }^{5}$

In order to account for the design effects of the sample, whereby students are nested within schools, we present clustered standard errors (StataCorp 2007). Following Winship and Radbill (1994), we decided to present unweighted regression analyses, since weighted regression models provide less efficient estimates of the parameters. The regression models each include as the stratifiers (indicators of the specific demographic groups that were oversampled in Add Health) as controls in our regressions models. We also estimated weighted regression analyses, which were largely consistent with our findings from the unweighted models. When presenting the findings below, we note any differences between the weighted and unweighted results.

To address missing data due to item non-response for the covariates in the analyses, we created five multiply imputed data sets using Stata's ICE platform (Royston 2005) ${ }^{6}$. As von Hippel (2007) recommends, the dependent variables were used as covariates to impute values for independent variables in our regression analyses, but for each analysis, cases with missing data on the dependent variable were excluded from the analyses. Missing values for students' friends/peers were imputed using a single imputation prediction before the measures of the 
average characteristics of one's social network were created. For each analysis, the standard errors were adjusted for the use of multiply imputed data.

\section{RESULTS}

\section{INSERT TABLE TWO ABOUT HERE}

\section{Predicting Grade Point Average}

We begin by examining how the characteristics of a student's friends, and his/her friends' friends, are related to GPA. Model one in table two shows the coefficients for our baseline model. Friends' GPA at time one is positively and significantly related to a student's own GPA at time two. In model 1 , the coefficient for friends' GPA $(0.14)$ indicates a one point increase in the average GPA of one's friends is associated with a 0.14 increase in one's own GPA. In model two, we add the GPA of a student's friends' friends to the regression, and the coefficient for this measure is substantively small and statistically insignificant. The coefficient for friends' GPA barely changes from model 1 to model 2, which indicates that for GPA the coefficient for friends' characteristics is not upwardly biased due to the omission of friends' friends' characteristics in model 1 . The coefficients in table 2 suggest a student's grades at time two are associated with their friends' grades, but not the grades of their friends' friends. However, it should be noted the coefficient for friends' GPA is quite small in magnitude: a difference of two full letter grades in one's friendship network (a four standard deviation difference) is associated with an increase of only one-quarter of a letter grade in a student's GPA at time two. In short, our findings suggest neither friends' nor friends-of-friends' grades are particularly important in predicting how students' academic grades change over time. ${ }^{7}$

\section{INSERT TABLE THREE ABOUT HERE}

Predicting College Expectations 
The second outcome of interest in our study is college expectations (at the second survey wave). Since the outcome variable is dichotomous, we estimated logistic regression models, and present log odds coefficients in table two. As with "grade point average," we present two models in table three. The first model (model one) includes all of our control variables, prior college expectations, and the students' friends' high college expectations. We include a dummy variable for whether each student reported "certainty" in graduating from college at time one to the regression in order to account for the fact students with higher expectations are more likely to select friends with similar expectations.

In model one, we see a student's friends' expectations at time one are positively and significantly related to their chances of having high college expectations at time two. In model two, friends' friends' expectations are added to the model, and the coefficient is positive and statistically significant. The coefficient for friends' friends' college expectations $(0.42)$ is actually larger than the coefficient for friends' college expectations (0.28), although a Wald test indicates the coefficients are not significantly different at $p<.05$. The coefficient for friends' college expectations declines only slightly from model 1 to model 2 when friends' friends' expectations are added to the model. ${ }^{8}$ Thus, it does not appear that the coefficient for friends' college expectations is substantially upwardly biased when friends-of-friends' expectations are omitted from the model, and the two variables are independently associated with students' educational expectations at time two.

To understand the magnitude of the associations, we plotted the predicted probabilities of having high expectations at time two based on a student's friends' and friends' friends' expectations at time one in Figure 2. The solid red line displays the relationship between a student's predicted probability of having high expectations and the college expectations of 
his/her friends. The $\mathrm{x}$-axis represents the full range of observed values on friends' expectations ('0', which means no friends have high expectations, vs. ' 1 ' which indicates that $100 \%$ of friends have high expectations). If we compare two students who are one standard deviation above and below the mean for friends' expectations (.26 vs. .80), we see that a student's predicted probability of having high expectations increases from about .55 to .58 .

Figure two also plots the combined (additive) impact of changes in the students' friends' and friends' friends' expectations (represented by the blue dashed line) on their own expectations. While the first (red, solid) line holds friends' friends' expectations at the mean, the second (blue, dashed) line describes the change in the predicted probability as both friends' and friends' friends' expectations are changing with the same values along the x-axis. Not surprisingly, this line is steeper than the red "friends only" slope since the two measures have largely independent associations with the outcome. When we compare students along the same range on the $\mathrm{x}$-axis as we did for the first line (.26 vs. .80), we see a larger change in the predicted probability of having high college expectations, increasing from .53 to .60 . Thus, Figure 2 demonstrates that the characteristics of both a student's friends and his/her friends' friends is associated with a larger predicted change in a student's own expectations (roughly twice as large) than that of friends' expectations alone.

\section{INSERT TABLE FOUR ABOUT HERE}

\section{Predicting High School Drop Out}

The findings presented in table four examine how the characteristics of students' friends and his/her friends' friends affect the likelihood of dropping out of high school. Our logistic regression models predicting dropout include our control variables and the risk factors associated with a student's chances of dropping out. Model one includes our indicator of a student's friends' 
dropout risk at time one, as a predictor of whether the student failed to finish high school by the end of wave three. We find a significant, positive relationship between the drop out risk of one's friends and one's own risk of dropping out. Students with more school friends (network size) are less likely to drop out (although this relationship is does not remain significant in model two). Also, social isolates, who did not report any friendships at time one, are more likely to drop out than students who made at least one in-school friendship nomination.

Model two of table four adds the dropout risk of one's friends' friends to the model. There is a strong, positive association between the dropout risk of a student's friends' friends and his/her own likelihood of dropping out. The size of the coefficient for the dropout risk of friends' friends is more than twice as large as the magnitude of a student's friends' dropout risk. ${ }^{9}$ However, a Wald Test indicates the coefficients for friends' and friends of friends' dropout risk in model two are not significantly different from each other at the $\mathrm{p}<.05$ threshold $(\mathrm{p}=.07)$. The coefficient for friends' dropout risk is reduced by one-third from model 1 to model 2 when the dropout risk of friends' friends is included in the model. This indicates the estimated relationship between friends' characteristics and a student's likelihood of dropping out is modestly upwardly biased when friends' friends' characteristics are not included in the model.

In figure 3, we display predicted probabilities of a student dropping out based upon his/her friends' and friends of friends' characteristics in order to assess the differing magnitude of these relationships. The solid red line shows, when friend's dropout risk alone increases from 0 to .30 a student's own probability of drop out increases by $50 \%$ (from .11 to .16). In contrast, the dashed blue line indicates how additive changes in both a student's friends' and his/her friends' friends are associated the predicted probability of dropping out. As the average dropout risk of one's friends and friends' friends increases from 0 to .30, a student's own probability of 
dropping out more than triples (from .07 to .24). Figure 3 demonstrates that, in contrast with models that only include measures of students' immediate friendship ties, the drop out risk of both a student's friends and his/her friends' friends is associated with a larger predicted change in a student's own risk of dropping out (roughly three times greater).

\section{INSERT TABLE FIVE ABOUT HERE}

\section{Accounting for Local Position}

One possible explanation for our findings is that our measures of friends' friends' characteristics are tapping into larger peer networks, such as a student's coursemates. In this section, we report the results of supplementary analyses to address this issue by accounting for the influence of an alternative measure of the intermediate social context used in prior research: students' local position. Frank et al. (2008) define the local position as "a set of students within a school who participate in a set of courses that differentiate them from other students in the school" (p.1654). This measure is a useful indicator of an intermediate peer context that identifies distinct subgroups within the broader school context. These course-mates represent the in-school peer network that students interact with most regularly during the school day. The local position also serves as a larger pool (than friends' friends) of "future friends" for students (Frank et al. 2008). ${ }^{10}$

Table five shows the correlations between the characteristics for students' friends, their friends' friends, and the peers within their local position. The correlations between friends' and friends' friends' characteristics (.61 for GPA, .28 for college expectations, and .49 for dropout risk) are stronger than the correlations between each of these measures and the local position measures (ranging between .26 and .11). This pattern of correlations indicates that students' friends' friends are considerably more similar to students' own friends than the broader set of 
peers in their local position. Thus, our findings suggest that the friends of a student's friends do not strongly resemble the peers in a student's local position.

To adjust for the correlations between our friends-of-friends and local position measures, we re-estimated our regression models (presented in tables 2-4) with a measure of the characteristics of the local position as a predictor in the model. (See on-line appendix.) Reestimating the analyses with the local position measures substantially reduces our sample size (to roughly 4,000 for GPA and expectations, and 5,600 for dropout) because local position membership is identified by using information from students' course-taking patterns provided in high school transcripts, and not all students had transcript information in the data. Accordingly, we re-estimated the "full models" from tables two through four, using the reduced sample of cases that contains valid information about a student's local position. These models served as our new baseline for comparison.

These new baseline models produced coefficients that were largely consistent with the full models presented in table two through four, both in magnitude and statistical significance. ${ }^{11}$ The peers in a student's local position were only significantly related to the risk of completing high school (but not grades or college expectations). However, the most important finding in this sensitivity analysis was the stability of the coefficients (both in magnitude and significance) for friends' and friends' friends' characteristics before and after controlling for local position. This pattern of results suggests that the relationships observed in tables two through four are not driven by the similarity between the characteristics of students' friends, their friends-of-friends, and the peers in their local position. In short, friends' and friends' friends' characteristics have relationships with the outcomes in our analyses that are largely independent of the characteristics of a student's local position. 


\section{DISCUSSION}

In this study, we examined how the "intermediate" peer context is related to students" academic outcomes. Based on prior theories and research, we focused on the friends of a student's friends as a key set of actors who may influence students' educational outcomes through several different mechanisms, such as students' attempts solidify their own friendship ties, or possibly establish new friendship ties with these peers. Our study makes three main contributions to the literature.

Our first contribution entails describing whether friends-of-friends' characteristics were significantly related to students' academic outcomes. We predicted friends-of-friends' characteristics would matter for college expectations and high school completion, outcomes that are likely to be affected by attitudinal and behavioral conformity to the intermediate peer context. Our findings were consistent with this expectation: friends' friends' characteristics were significantly associated with student expectations and high school dropout (but not student GPA), even after controlling for students' own characteristics and the characteristics of students' friends. Indeed, our models predicting student expectations and high school dropout produced coefficients for friends-of-friends characteristics that were roughly as large in magnitude as the coefficients for students' friends' characteristics. Thus, our findings indicate both direct friendship ties, and the intermediate peer context (friends' friends) are important for adolescents' schooling outcomes. Our study adds to a growing body of research that indicates friends-offriends' characteristics are important for adolescent outcomes, such as deviance and crime (Giordano 2003; Kreager and Haynie 2011; Payne and Cornwell 2007), mental health (Baller and Richardson 2009), and physical health (Christakis and Fowler 2007). 
Our findings are consistent with our theoretical framework. If conformity is a commonly used strategy to solidify current friendships (Payne and Cornwell 2007), or to lay the groundwork for new friendships (Flashman 2012; Kandel 1978), then we would expect peers just outside of one's friendship network - friends-of-friends - to be important in shaping student behavior and outcomes. While our analyses do not reveal why friends' friends' characteristics matter, our results are certainly consistent with the argument that students engage in attitudinal and behavioral conformity in an attempt to make new friends (Frank et al. 2008) or to solidify their own friendships (Payne and Cornwell 2007).

In contrast, we found a student's friends' GPA, but not his/her friends' friends' GPA, significantly predicted his/her GPA. This pattern is also consistent with our hypothesis that direct, but not indirect, social ties to friends were likely useful in helping students with their school work. Students can learn directly from their friends' content knowledge and academic skills (through diffusion), which would influence their learning. In contrast, the GPA of one's friends' friends are of limited value to one's own academic performance, since grades are typically not shared publicly and group studying mostly occurs among friends.

Our second contribution relates to whether measures of friends' characteristics produced upwardly biased estimates when failing to control for friends-of-friends' characteristics. Overall, we found our measures of friends' and friends-of-friends' characteristics largely worked independently of each other. For grades and student expectations, there was little change in the coefficients for friends' characteristics when friends' friends' characteristics were added as controls in the models. For dropping out, the coefficient for friends' dropout risk decreased by about one-third when controlling for friends' friends' dropout risk, which is a modest reduction in bias. Ultimately, it appeared that friends' and friends-of-friends' characteristics had largely 
independent relationships with educational expectations and high school completion. This is an important finding because it suggests prior studies of friends' influence on students' outcomes are not overestimating the importance of friends in their analyses (e.g., Cook et al. 2007; South et al. 2007; Vaquera and Kao 2008).

Finally, our third contribution focused on the cumulative effects of friend and friends-offriend networks on student outcomes. Our findings indicate that the combined association of students' friend and friend-of-friend networks are considerably larger when they are accounted for in the same model. In other words, we observe a considerably stronger relationship with student outcomes when students have alignment between the college expectations and dropout risk of their friends and friends-of-friends. Thus, prior research that solely focuses on friends' characteristics systematically underestimates the potential cumulative impact of the broader peer context on student outcomes.

It is important to highlight a key limitation of our study. As Mouw (2006) noted, selfselection is a major challenge in all studies of social networks, and we acknowledge it is difficult to make inferences about causality from our analyses. Some features of our study may minimize the importance of this issue. First, while students clearly select (and are also selected by) the members of their friendship network, they do not directly select their friends' friends. Rather, the selection process is indirect: friends-of-friends are "chosen" indirectly via the friendships that students form. Perhaps students look to friends-of-friends to help determine who would be a good friend, but we suspect this is (at best) a secondary consideration in friendship formations. Thus, self-selection is likely a less serious problem in studying friends-of-friends than it is in examining student friendship networks. 
Second, our analyses are designed to take advantage of the longitudinal design of Add Health. We include lagged measures of the dependent variable included in our models, and the friends' and friends-of-friends' characteristics are measured prior to the observed outcomes. These design features use "time-ordering" to reduce the impact of initial self-sorting on our analyses. These models are a marked improvement over cross-sectional models that rely upon one wave of data because they allow us to examine how student characteristics change in association with prior friends' and friends' friends' characteristics. However, we acknowledge our models cannot address the exact sequence of events that leads to changes in student outcomes over time. Do students make new friendships and which leads to change in the outcome, or do students change their behavior, which in turn leads to the formation of new friendships? Or, do friends-of-friends affect student outcomes without ever leading to the formation of direct friendship ties?

Our analyses cannot address these questions, but panel data with measures of student and friend characteristics at multiple time points would offer an opportunity to explore how networks and student outcomes co-evolve over time. Lomi et al. (2011) provide an excellent example of how these questions might be addressed with longitudinal data and stochastic agent based models. Similarly, Flashman (2012) analyzed the small subsample of "saturated" schools in Add Health with three waves of friendship data, but unfortunately, these schools are quite different from the full sample of students in schools that we analyzed. Future research might fruitfully explore these questions about causal sequencing, although we suspect that many time points within subjects are needed to tease out the causal ordering of friendship formation and changing outcomes for students. 
We hope our analyses will stimulate a more theoretically nuanced framework for understanding how both friendship ties and the intermediate peer context are related to student outcomes. Our research is motivated by recent calls for a more theoretically coherent framework for studying peer effects (e.g., Akerloff and Kranton 2010; Harris 2010), and we hope our analyses expand the scope of future research to examine intermediate peer contexts in empirical analyses. In addition, our research should be viewed as complementary to prior studies that focus on the importance of friendship ties. Our findings are consistent with the well-established finding that "friends matter," but we argue future research should recognize that the friendship network is only one part of the larger set of social relations that shape student outcomes. 


\section{WORKS CITED}

Akerlof, George and Rachel Kranton. 2010. Identity Economics: How Our Identities Shape Our Work, Wages, and Well-being. Princeton, New Jersey: Princeton University Press.

Baller, Robert and Kelly Richardson. 2009. "The "Dark Side" of the Strength of Weak Ties: The Diffusion of Suicidal Thoughts." Journal of Health and Social Behavior 50:261-76.

Battin-Pearson, Sara, Michael Newcomb, Robert Abbott, Karl Hill, Richard Catalano and J. David Hawkins. 2000. "Predictors of Early High School Dropout: A Test of Five Theories." Journal of Educational Psychology 92:568-582.

Berndt, Thomas and Keunho Keefe. 1995. "Friends Influence on Adolescents Adjustment to School." Child Development 66:1312-1329.

Brown, B. Bradford, Margaret Mory, and David Kinney. 1994. "Casting Adolescent Crowds in a Relational Perspective.” Pp. 123-67 in (Ed.s) Raymond Montemayor, Gerald Adams, and Thomas Gullota. Personal Relationships During Adolescence Sage Publications, Thousand Oaks, CA.

Cairns, Robert, Beverly Cairns and Holly Neckerman. 1989. "Early School Dropout Configurations and Determinants." Child Development 60:1437-1452.

Call, Kathleen and Jeylan Mortimer. 2001. Arenas of Comfort in Adolescence: A Study of Adjustment in Context. Mahwah, New Jersey: Laurence Erlbaum Associates.

Carter, Prudence. 2007. Keepin' It Real: School Success beyond Black and White. New York: Oxford University Press.

Christakis, Nicholas and James Fowler. 2007. "The Spread of Obesity in a Large Social Network Over 32 Years." New England Journal of Medicine 357:370-379. 
Christakis, Nicholas and James Fowler. 2008. "The Collective Dynamics of Smoking in a Large Social Network." New England Journal of Medicine 358:2249-2258.

Coleman, James. 1961. The Adolescent Society. Oxford, England: The Free Press of Glencoe.

Cook, Thomas, Yingying Deng, and Emily Morgano. 2007. "Friendship Influences During Early Adolescence: The Special Role of Friends' Grade Point Average." Journal of Research on Adolescence 2:325-56.

Eckert, Penelope. 1989. Jocks and Burnout: Social Categories and Identity in the High School. New York: Teachers College Press.

DiMaggio, Paul and Filiz Garip. 2012. "Network effects and social inequality." Annual Review of Sociology 38:93-118.

Farmer, Thomas, David Estell, Man-Chi Leung, Hollister Trott, Jennifer Bishop, and Beverly Cairns. 2003. "Individual Characteristics, Early Adolescent Peer Affiliations, and School Dropout: An Examination of Aggressive and Popular Group Types.” Journal of School Psychology 41:217-232.

Flashman, Jennifer. 2012. "Academic Achievement and Its Impact on Friend Dynamics." Sociology of Education 85:61-80.

Frank, Kenneth, Chandra Muller, Kathryn Schiller, Catherine Riegle-Crumb, Anna Strassmann Mueller, Robert Crosnoe, and Jennifer Pearson. 2008. "The Social Dynamics of Mathematics Coursetaking in High School." American Journal of Sociology 113:1645-96. Giordano, Peggy. 1995. “The Wider Circle of Friends in Adolescence.” American Journal of Sociology 101:661-97. 
. 2003. "Relationships in Adolescence." Annual Review of Sociology 29:257-

281.

Hallinan, Maureen and Richard Williams. 1991. 'Students' Characteristics and the PeerInfluence Process." Sociology of Education 63: 122-132.

Hanushek, Eric and Stephen Rivkin. 2006. "School Quality and the Black-white Achievement Gap.” (Working Paper No. 12651). Cambridge, MA: National Bureau of Economic Research.

Harris, Douglas. 2010. "How Do School Peers Influence Student Educational Outcomes? Theory and Evidence from Economics and Other Social Sciences." Teachers College Record 11: 828.

Harris, Kathleen, Carolyn Halpern, Eric Whitsel, Jon Hussey, Joyce Tabor, Pamela Entzel, and J. Richard Udry. 2009. The National Longitudinal Study of Adolescent Health: Research Design [WWW document]. URL:http://www.cpc.unc.edu/projects/addhealth/design.

Hauser, Robert M., Shu-Ling Tsai and William H. Sewell. 1983. "A Model of Stratification with Response Error in Social and Psychological Variables." Sociology of Education 56:20-46.

Hollingshead, August. 1941. Elmstown Youth: The Impact of Social Classes on Adolescents. New York: John Wiley and Sons.

Jimerson, Shane, Byron Egeland, L. Alan Sroufe and Betty Carlson. 2000. "A Prospective Longitudinal Study of High School Dropouts Examining Multiple Predictors across Development." Journal of School Psychology 38:525-549.

Kandel, Denise. 1978. "Homophily, Selection, and Socialization in Adolescent Friendships." American Journal of Sociology 84:427-36. 
Kinney, David. 1993. "From Nerds to Normals: The Recovery of Identity among Adolescents from Middle School to High School.” Sociology of Education 66:21-40.

Konstantopoulos, Spyros. 2006. "Trends of School Effects on Student Achievement: Evidence from NLS:72, HSB:82, and NELS:92.” Teachers College Record 108: 2550-2581.

Kossinets, Gueorgi and Duncan J. Watts. 2006. "Empirical Analysis of an Evolving Social Network." Science :88-90.

Kreager, Derek A. and Dana L. Haynie. 2011. "Dangerous Liaisons? Dating and Drinking Diffusion in Adolescent Peer Networks." American Sociological Review 76:737-763.

Lomi, Alessandro, Tom A. B. Snijders, Christian E. G. Steglich and Vanina J. Torló. 2011. "Why are some more peer than others? Evidence from a longitudinal study of social networks and individual academic performance." Social Science Research 40:1506-1520.

MacLeod, Jay. 2010. Ain't No Makin' It: Aspirations and Attainment in a Low-income Neighborhood, Expanded Edition. Boulder, CO: Westview Press.

McPherson, Miller, Lynn Smith-Lovin and James M. Cook. 2001. "Birds of a Feather: Homophily in Social Networks." Annual Review of Sociology 27:415-444.

Milner, Murray. 2006. Freaks, Geeks, and Cool Kids: American Teenagers, Schools, and the Culture of Consumption. New York: Routledge.

Moody, James. 2001. "Race, School Integration, and Friendship Segregation in America." American Sociological Review107:679-716.

Mouw, Ted. 2006. "Estimating the causal effect of social capital: A review of recent research." Annual Review of Sociology 32:79-102. 
Ogbu, John. 2003. Black Students in an Affluent Suburb. Mahwah: NJ: Lawrence Erlbaum Associates.

Payne, Danielle and Benjamin Cornwell. 2007. "Modeling Peer Influences on Delinquency: Beyond the Direct Contact Hypothesis." Journal of Quantitative Criminology 23:127-150.

Perry, Laura and Andrew McConney. 2010. "Does the SES of the School Matter? An Examination of Socioeconomic Status and Student Achievement Using PISA 2003.” Teachers College Record 112.

Ream, Robert and Russell Rumberger. 2008. "Student Engagement, Peer Social Capital, and School Dropout among Mexican American and Non-Latino White Students." Sociology of Education 81:109-139.

Royston, Patrick. 2005. "Multiple Imputation of Missing Values: Update.” Stata Journal 5: 188204.

Rumberger, Russell and Gregory Palardy. 2005. "Does Segregation Still Matter? The Impact of Social Composition on Academic Achievement in High School." Teachers College Record 107:1999-2045.

Savin-Williams, Ritch and Thomas Brendt. 1990. "Friendship and Peer Relations." In Feldman, S. Shirley and Glen Elliot (eds), At the Threshold: The Developing Adolescent. Harvard University Press: Cambridge.

South, Scott, Dana Haynie and Sunita Bose. 2007. "Student Mobility and School Dropout." Social Science Research 36:68-94.

StataCorp. 2007. Stata Statistical Software: Release 10. College Station, TX: StataCorp LP. Steinberg, Laurence. 1996. Beyond the Classroom: Why School Reform Has Failed and What Parents Need To Do. New York: Simon \& Schuster. 
Vaquera, Elizabeth and Grace Kao. 2006. "Do You Like Me as Much As I Like You? Friendship Reciprocity and Its Effects on School Outcomes among Adolescents.” Social Science Research 37:55-72.

von Hippel, Paul. 2007. “Regression with Missing Y's: An Improved Strategy for Analyzing Multiply Imputed Data.” Sociological Methodology 37: 83-117.

Willms, Douglas. 2010. "School Composition and Contextual Effects on Student Outcomes." Teachers College Record 112.

Winship, Christopher and Larry Radbill. 1994. "Sampling Weights and Regression Analysis." Sociological Methods \& Research 23: 230-257. 
Table One: Descriptive Statistics of Variables Included in Analytical Models

\begin{tabular}{|c|c|c|c|c|c|}
\hline Variables & $\begin{array}{r}\text { Number of } \\
\text { Observations }\end{array}$ & Mean & $\begin{array}{l}\text { Standard } \\
\text { Deviation }\end{array}$ & Min & Max \\
\hline \multicolumn{6}{|l|}{$\begin{array}{l}\text { INDEPENDENT VARIABLES } \\
\text { Wave One, In-School } \\
\text { (September 1994-April 1995) }\end{array}$} \\
\hline \multicolumn{6}{|l|}{ Student Characteristics } \\
\hline \multicolumn{6}{|l|}{ Prior Grades } \\
\hline B Average & 7,719 & 0.30 & 0.46 & 0.00 & 1.00 \\
\hline C Average & 7,719 & 0.39 & 0.49 & 0.00 & 1.00 \\
\hline D Average & 7,719 & 0.21 & 0.41 & 0.00 & 1.00 \\
\hline PPVT Score & 10,369 & 52.51 & 28.84 & 0.00 & 100.00 \\
\hline Deviance & 10,369 & 1.11 & 1.05 & 0.00 & 6.00 \\
\hline Number of Extracurricular Activities & 10,369 & 2.41 & 2.13 & 0.00 & 10.00 \\
\hline School Attachment & 10,369 & 3.57 & 0.97 & 1.00 & 5.00 \\
\hline School Engagement & 10,369 & 3.20 & 1.25 & 1.00 & 5.00 \\
\hline \multicolumn{6}{|l|}{ Friend and Peer Characteristics } \\
\hline \multicolumn{6}{|l|}{ GPA of: } \\
\hline Friends & 7,719 & 2.85 & 0.49 & 1.00 & 4.00 \\
\hline Friends' Friends & 7,719 & 2.85 & 0.36 & 1.00 & 4.00 \\
\hline \multicolumn{6}{|l|}{ High College Expectations of: } \\
\hline Friends & 7,820 & 0.53 & 0.27 & 0.00 & 1.00 \\
\hline Friends' Friends & 7,820 & 0.54 & 0.28 & 0.00 & 1.00 \\
\hline \multicolumn{6}{|l|}{ Drop Out Risk of: } \\
\hline Friends & 10,369 & 0.11 & 0.08 & 0.01 & 0.75 \\
\hline Friends' Friends & 10,369 & 0.13 & 0.05 & 0.02 & 0.65 \\
\hline \multicolumn{6}{|l|}{ Network Size } \\
\hline Number of Friends & 10,369 & 5.44 & 3.37 & 0.00 & 10.00 \\
\hline No Friends & 10,369 & 0.14 & 0.35 & 0.00 & 1.00 \\
\hline Number of Friends' Friends & 10,369 & 18.84 & 14.28 & 0.00 & 74.00 \\
\hline Closed Social Group & 10,369 & 0.12 & 0.32 & 0.00 & 1.00 \\
\hline \multicolumn{6}{|l|}{ Background Characteristics } \\
\hline Parental Dropout & 10,369 & 0.12 & 0.32 & 0.00 & 1.00 \\
\hline Parental College & 10,369 & 0.44 & 0.50 & 0.00 & 1.00 \\
\hline Black & 10,369 & 0.18 & 0.39 & 0.00 & 1.00 \\
\hline Hispanic & 10,369 & 0.06 & 0.23 & 0.00 & 1.00 \\
\hline Asian & 10,369 & 0.07 & 0.26 & 0.00 & 1.00 \\
\hline Native American & 10,369 & 0.01 & 0.10 & 0.00 & 1.00 \\
\hline Multiple Race & 10,369 & 0.18 & 0.39 & 0.00 & 1.00 \\
\hline Female & 10,369 & 0.55 & 0.50 & 0.00 & 1.00 \\
\hline Grade Level & 10,369 & 9.65 & 1.61 & 6.00 & 12.00 \\
\hline Born in the United States & 10,369 & 0.91 & 0.28 & 0.00 & 1.00 \\
\hline
\end{tabular}


DEPENDENT VARIABLES

Wave One, In Home

(April 1995- December 1995)

GPA

High College Expectations

7,719

2.85

0.761 .00

4.00

Wave Three, In Home (August2001- April

7,820

0.57

$0.50 \quad 0.00$

1.00

2002)

High School Drop Out

10,369

0.13

$0.33 \quad 0.00$

1.00 
Table Two: OLS Regression Coefficients of GPA on Friends' and Friends' Friends' GPA

\begin{tabular}{|c|c|c|}
\hline & Model 1 & Model 2 \\
\hline \multirow[t]{2}{*}{ Friends' GPA } & $0.14 * * *$ & $0.13^{* * *}$ \\
\hline & $(0.02)$ & $(0.02)$ \\
\hline \multirow[t]{2}{*}{ \# of Friends } & 0.00 & $0.01^{* *}$ \\
\hline & $(0.00)$ & $(0.00)$ \\
\hline \multirow[t]{2}{*}{ No Friends } & -0.02 & -0.00 \\
\hline & $(0.02)$ & $(0.03)$ \\
\hline \multirow[t]{2}{*}{ Friends' Friends' GPA } & & 0.03 \\
\hline & & $(0.02)$ \\
\hline \multirow[t]{2}{*}{ \# of Friends' Friends } & & $-0.00 *$ \\
\hline & & $(0.00)$ \\
\hline \multirow[t]{2}{*}{ No Friends' Friends } & & -0.03 \\
\hline & & $(0.03)$ \\
\hline \multicolumn{3}{|l|}{ Prior Grades (Wave 1) } \\
\hline \multirow[t]{2}{*}{ B Average } & $-0.32 * * *$ & $-0.32 * * *$ \\
\hline & $(0.02)$ & $(0.02)$ \\
\hline \multirow[t]{2}{*}{ C Average } & $-0.81 * * *$ & $-0.81 * * *$ \\
\hline & $(0.02)$ & $(0.02)$ \\
\hline \multirow[t]{2}{*}{ D Average } & $-1.25^{* * *}$ & $-1.25 * * *$ \\
\hline & $(0.03)$ & $(0.03)$ \\
\hline \multirow[t]{2}{*}{ Intercept } & $2.93 * * *$ & $2.88 * * *$ \\
\hline & $(0.13)$ & $(0.14)$ \\
\hline R-squared & 0.55 & 0.55 \\
\hline
\end{tabular}

Note: $n=7,719$ for both models. All coefficients are unstandardized, and standard errors are presented in parentheses. All models include controls for: parental education, race, gender, grade level, native U.S. born, student deviance, college expectations, school attachment, school engagement, and PPVT score.

$* p<.05 * * p<.01 * * * p<.001$ (two-tailed test) 
Table Three: Logistic Regression Coefficients of High College Expectations on Friends' and Friends' Friends' High College Expectations

\begin{tabular}{lll}
\hline & Model 1 & Model 2 \\
\hline Friends' High College & & \\
Expectations & $0.31^{* *}$ & $0.27^{*}$ \\
& $(0.11)$ & $(0.11)$ \\
\# of Friends & $0.04^{* *}$ & 0.03 \\
& $(0.01)$ & $(0.02)$ \\
No Friends & 0.21 & 0.22 \\
& $(0.11)$ & $(0.15)$ \\
Friends' Friends High & & $0.42^{*}$ \\
College Expectations & & $(0.18)$ \\
\# of Friends' Friends & & 0.00 \\
& & $(0.00)$ \\
No Friends' Friends & & -0.03 \\
& & $(0.15)$ \\
Prior Expectations & $1.21^{* * *}$ & $1.19^{* * *}$ \\
High College Expectations (W1) & $(0.06)$ & $(0.06)$ \\
Intercept & $-5.27^{* * *}$ & $-5.44^{* * *}$ \\
& $(0.52)$ & $(0.52)$ \\
-2 Log Likelihood & -4072.55 & -4069.68 \\
\hline
\end{tabular}

Note: $n=7,820$ for both models. All coefficients are presented in the log odds metric, and standard errors are presented in parentheses. All models include controls for: parental education, race, gender, grade level, native U.S. born, student deviance, school attachment, school engagement, and PPVT score.

$* p<.05 * * p<.01 * * * p<.001$ (two-tailed test) 
Table Four: Logistic Regression Coefficients of High School Drop Out on Friends' and Friends' Friends' Drop Out Risk

\begin{tabular}{lll}
\hline & Model 1 & Model 2 \\
\hline Friends' Dropout Risk & $0.27^{* * *}$ & $0.19^{* * *}$ \\
& $(0.05)$ & $(0.05)$ \\
\# of Friends & $-0.03^{*}$ & 0.00 \\
& $(0.01)$ & $(0.02)$ \\
No Friends & $0.60^{* * *}$ & $0.66^{* * *}$ \\
& $(0.14)$ & $(0.17)$ \\
Friends' Friends' Dropout Risk & & $0.38^{* * *}$ \\
& & $(0.08)$ \\
\# of Friends' Friends & & $-0.01^{*}$ \\
& & $(0.00)$ \\
No Friends' Friends & & -0.12 \\
& & $(0.15)$ \\
Intercept & & $3.08^{* * *}$ \\
& $3.51^{* * *}$ & $(0.60)$ \\
-2 Log Likelihood & $(0.59)$ & -3049.59 \\
\hline
\end{tabular}

Note: $n=10,369$ for models one and two. All coefficients are presented as the log odds metric, and standard errors are presented in parentheses. All models include controls for: parental education, race, gender, grade level, native U.S. born, student deviance, school attachment, school engagement, and PPVT score.

$* \mathrm{p}<.05 * * \mathrm{p}<.01 * * * \mathrm{p}<.001$ (two-tailed test) 
Table Five: Correlation of the Characteristics of Students' Friends, Friends' Friends, and Local Position Members

\begin{tabular}{rcc}
\hline & \multicolumn{2}{c}{ GPA } \\
& \multicolumn{2}{c}{$(\mathrm{n}=5,907)$} \\
\hline & Friends & Friends' Friends \\
\hline $\begin{array}{r}\text { Friends' Friends } \\
\text { Local Position }\end{array}$ & $0.61^{* * *}$ & -- \\
& High College Expectations \\
& \multicolumn{2}{c}{ (n=6,003) } \\
\hline & Friends & Friends' Friends \\
\hline Friends' Friends & $0.28^{* * *}$ & -- \\
Local Position & $0.15^{* * *}$ & $0.17^{* * *}$ \\
\hline & \multicolumn{2}{c}{ Dropout Risk } \\
\hline & \multicolumn{2}{c}{ (n=5,895) } \\
\hline Friends' Friends & $0.49^{* * *}$ & Friends' Friends \\
Local Position & $0.11^{* * *}$ & $0.20^{* * *}$ \\
\hline
\end{tabular}

Note: Pearson correlations are presented.

$* * * p<.001$ (two-tailed test) 
Figure One: Sociogram Comparing Ties to Ego's Friends and his/her Friend's Friends

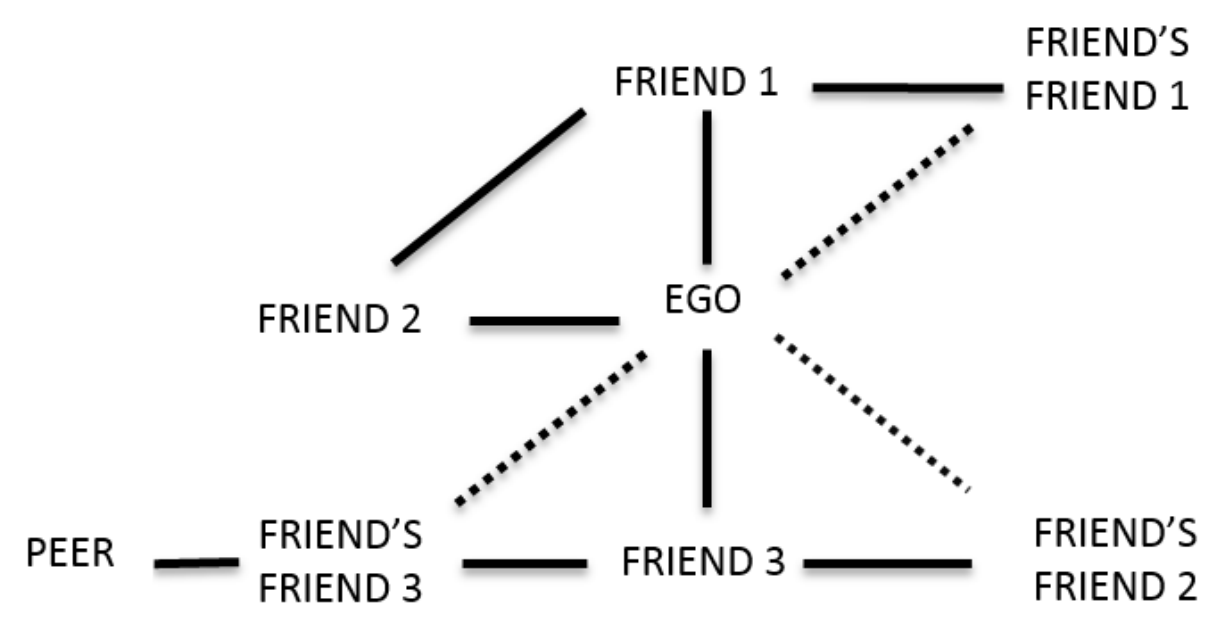

Friendship Tie _....... Indirect (Intransitive) Tie with Ego 
Figure 2: Predicted Probability of High College Expectations by Friends' and Friends' Friends' College Expectations

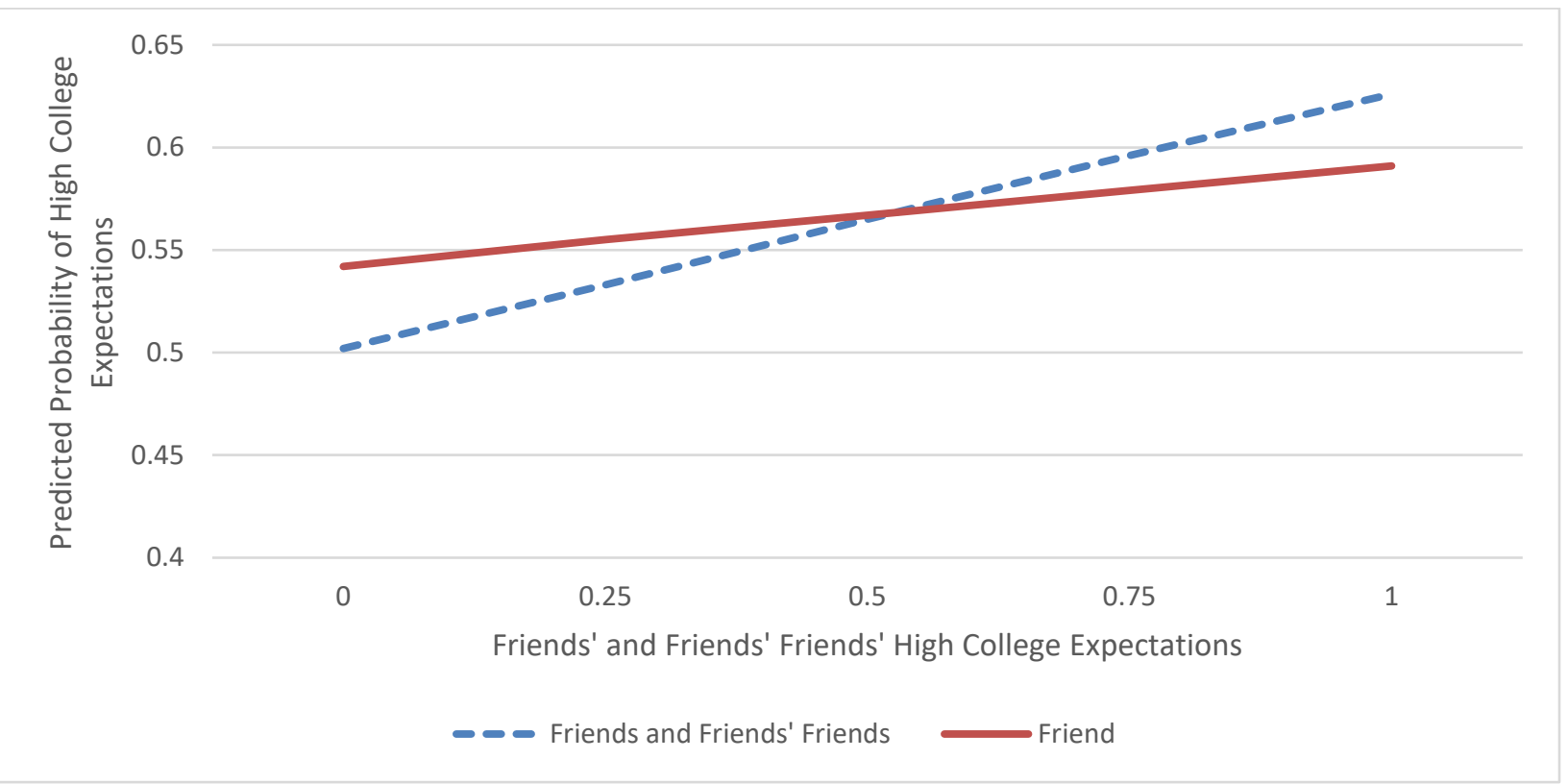

Figure 3: Predicted Probability of Dropping Out by Friends' and Friends' Friends' Drop Out Risk

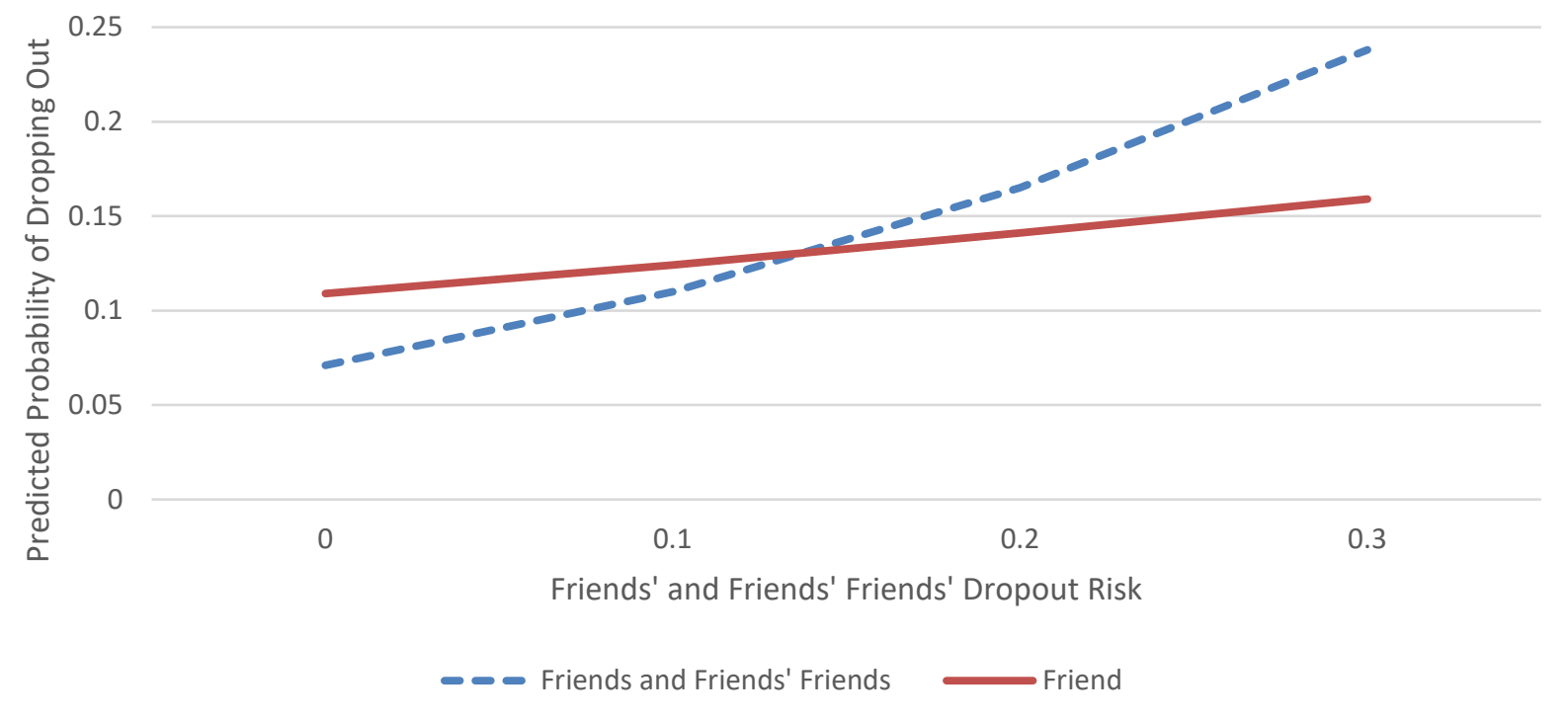




\section{ENDNOTES}

${ }^{1}$ Generally, studies of friends and school composition focus on one group to the exclusion of the other (e.g., Battin-Pearson et al. 2000; Berndt and Keefe 1995; Cairns, Cairns, and Neckerman 1989; Farmer et al. 2003; Hallinan and Williams 1991; Ream and Rumberger 2008; Rumberger and Palardy 2005; Vaquera and Kao 2008).

${ }^{2}$ Schools that had less than $50 \%$ of eligible students participate in the in-school survey are excluded from the analyses presented in this paper. Low levels of participation are likely to lead to inaccurate representations of the friendship networks of students who attend these schools. This restriction leads to 250 students in 8 schools being excluded from the sample.

${ }^{3}$ The one exception is an individual's PPVT score which was measured in the first wave of inhome data collection, in the spring of 1995.

${ }^{4}$ The summary measure of probability of drop out was created by estimating a logistic regression which examined how the six achievement-related characteristics used in this study are related to school completion while not controlling for background and school characteristics. Thus, for students who had valid degree attainment information, we observed how his/her GPA, number of extracurricular activities, attachment to school, engagement, deviance, and whether the student had high college expectations in the initial wave of data collection were related to eventual degree attainment. For each student who participated in the first wave of data collection, we generated his/her propensity for dropout by taking each of his/her observed achievement related characteristics and multiplying by the characteristic's association with dropout (the coefficient from the logistic regression). 
${ }^{5} \mathrm{We}$ also estimated models that did not adjust for school level differences. These models produced findings that were very similar to the fixed effects models presented in tables two through four in this paper.

${ }^{6}$ We did not impute information for individuals where the question merely did not apply to the individual. For instance we did not impute a course grade in a science class if a student did not report taking a science course the previous semester. This leads to two instances where cases were dropped from the sample. First, thirteen students did not report taking a science, English, math, or history course and thus could have no GPA measure constructed. Also, four-hundred and four students reported not living with a mother/father, or adult guardian and thus could not have parental characteristics constructed. Finally, we exclude 215 individuals who had missing information on more than two-thirds of the variables included in the analyses.

${ }^{7}$ Not surprisingly, models that did not include base year controls for GPA showed substantially larger associations between friends' GPA and a student's own GPA at wave two. In addition, friends' friends' GPA had a positive, statistically significant relationship with student GPA in these models. We suspect that these findings are driven largely by self-selection due to homophily (which motivated us to include initial grades as a control in our models presented in table two).

${ }^{8}$ The weighted analyses show that the friends' expectation variable is slightly smaller (.21) with a larger standard error (.16), which no longer attains significance at .05.

${ }^{9}$ The weighted analysis produces a smaller, although still sizable coefficient of .283 for friends' friends' drop out risk. However, as Winship and Radbill (1994) predict, use of the weight increases the standard error - in this case doubling it - thereby making it insignificant at .05 . As 
noted earlier, Winship and Radbill recommend presenting the more credible unweighted parameters estimates.

${ }^{10}$ We adjusted for the overlap among the different levels of social context: friends-of-friends were not counted as members of students' local position.

${ }^{11}$ One difference worth noting was that the coefficient for friends' friends' high college expectations was not statistically significant in the re-analysis using the reduced sample. However, the point estimate (0.49) was very similar to our estimate in the original model $(0.42)$, and the standard error $(.25)$ provided a p-value that was very close to the .05 threshold. 